21

22

24

18

19

20 Approved for publication by the Director of the Louisiana Agricultural Experiment Station as

23 Baton Rouge, LA 70803-4210.

\title{
Factors Affecting the Ovarian Response to a Combined Estradiol-Sulpiride Treatment in
} Seasonally Anovulatory Mares

(1)

(1)

(1)

\section{School of Animal Sciences, Louisiana Agricultural Experiment Station, Louisiana State University}

Agricultural Center, Baton Rouge, LA, USA

\section{Erin L. Oberhaus, Donald L. Thompson, Jr. and Carolyn K. Pham}

(1)

(1)

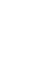

10

1

2

3

4

5

16

7

1 manuscript number 2016-230-30593.

22 Corresponding author at: E.L. Oberhaus, School of Animal Sciences, Louisiana State University,

4 E-mail address: eoberhaus@agcenter.lsu.edu (E.L. Oberhaus). 
Twenty-three seasonally anovulatory mares, housed at two separate farms, were treated

27 with $50 \mathrm{mg}$ of estradiol cypionate (ECP) and $3 \mathrm{~g}$ of sulpiride in January to study factors that 28 contributed to success of the treatment (response = ovulation within 28 days). Every-other-day

29 blood samples and pretreatment secretagogue challenges were used to characterize prolactin, LH, 30 IGF-I, leptin, and insulin concentrations. Ovaries of each mare were scanned via ultrasound 31 regularly until detection of a 32-35 $\mathrm{mm}$ follicle, at which time the mare was artificially

32 inseminated. Prolactin was stimulated in all treated mares and was similar $(P>0.05)$ in 33 responding and non-responding mares. Nine mares, all at the same farm $(\mathrm{BH}$; farm effect, $\mathrm{P}=$ 34 0.006), responded with pre-ovulatory sized follicles within 20 days of treatment. Five of the 9 35 were inseminated and 3 conceived. Retrospective analysis revealed that of the mares responding, 36 body condition score $(\mathrm{P}=0.03)$, body weight $(\mathrm{P}=0.02)$, plasma concentrations of insulin $(\mathrm{P}=$ 37 0.01) and leptin $(\mathrm{P}=0.09)$, and pretreatment response of $\mathrm{LH}$ to $\mathrm{GnRH}(\mathrm{P}=0.106)$ were higher in 38 responding than in non-responding mares. In general, factors that differed and may contribute to 39 whether a given mare responds to this ECP-sulpiride protocol were mainly characteristics 40 pointing towards well-nourished mares. Minor nutritional differences between farms likely 41 played a role in the lack of success on the one farm. Also, the LH response to GnRH prior to 42 treatment may be indicative of the subsequent $\mathrm{LH}$ response to ECP-sulpiride and hence the 43 ovarian response.

44

45 Key words: estradiol cypionate, mares, ovulation induction, seasonal anovulation, sulpiride 46 
Treatment with exogenous prolactin or an induced increase in endogenous prolactin

49 concentrations can advance the first ovulation in seasonally anovulatory mares [1-5]. Nequin et

50 al. [1] hastened follicular growth in deep anestrous mares with one treatment of ovine prolactin.

51 Thompson et al. [2] advanced the date to first ovulation in pony mares in winter by

52 administration of recombinant porcine prolactin, although antibodies to the injected prolactin

53 were eventually detected in those mares. In lieu of exogenous prolactin, various dopaminergic

54 antagonists such as sulpiride [3, 5-7], domperidone [4], and fluphenazine [1] have been used to

55 stimulate secretion of endogenous prolactin. Sulpiride and domperidone have been used most

56 frequently to stimulate prolactin secretion, a response greatly enhanced by pretreatment with

57 estradiol [6-8], which was also shown to stimulate luteinizing hormone (LH) in seasonally

58 anovulatory mares [6].

In a series of experiments, Mitcham et al. [8-10] compared prolactin and ovarian

60 responses in mares receiving various doses of estradiol cypionate (ECP) combined with either

61 domperidone or sulpiride, generally at 1.5 or 3.0 g injected 1 to 11 days after ECP injection.

62 Throughout 10 years of experimentation, success rates (percentage of mares ovulating within a

63 specified period of time) have varied from a high of 89\% [6] down to as low as 50\% for the more

64 simplified protocols (treatment with ECP and one injection of sulpiride). In general, mares that

65 respond do so within 28 days. Non-responding mares typically ovulate much later, interspersed

66 with control mares. The question that arises after each experiment is why some mares respond to

67 the selected treatment, whereas others do not. That is, what factor(s), either internal or external,

68 affect(s) whether a mare responds or not? 
The aim of the current experiment was to describe and measure as many factors as

70 possible that could potentially affect the response of a given mare. Towards this end, all

71 available anovulatory mares were treated in January with a standard protocol of ECP followed by

72 a single injection of sulpiride, and pretreatment assessments as well as real-time hormonal data

73 were retrospectively used to determine any differences between mares that responded and those

74 that did not respond in the first 28 days. Because previous experiments had not assessed fertility

75 of early ovulations induced by ECP and sulpiride, responding mares were also artificially

76 inseminated with semen from a single stallion once a 32-mm or larger follicle was detected.

77

\section{2. Materials and Methods}

Procedures used in these experiments were approved by the Institutional Animal Care and Use Committee of the Louisiana State University Agricultural Center.

\subsection{Animals}

Mares used in this experiment were housed at one of two Louisiana Agricultural

84 Experiment Station farms: the Central Research Station Horse Unit on the Ben Hur Plantation

$85(\mathrm{BH})$ and the Reproductive Biology Center (RBC). The two farms were located approximately 9

86 miles apart south of the Louisiana State University main campus in Baton Rouge. All mares were

87 maintained outdoors throughout the year. They grazed native grass pasture during the warmer

88 months and were supplemented with hay prepared from the same native grasses for ad libitum

89 consumption as needed in the fall and winter. In addition to this routine maintenance, mares at 
the BH farm were also supplemented in winter with $18 \%$ protein tubs (Positive Feed, Ltd.; Sealy,

$91 \mathrm{TX})$ and were limit-grazed on winter ryegrass pasture for 1 to 2 hours daily starting in January.

Starting in early December, 2015, all non-pregnant mares housed at the two farms were assessed by ultrasonic scanning of the ovaries once a week, and samples of jugular blood were collected approximately weekly. Anovulation was defined as the absence of any follicle $>20$ $\mathrm{mm}$, the absence of any corpora lutea, and plasma progesterone concentrations consistently less than $1 \mathrm{ng} / \mathrm{mL}$.

Twenty-three mares were identified that matched the criteria for anovulation: 14 from $\mathrm{BH}$ and 9 from RBC. They were all light horse mares, mainly Quarter Horses, Thoroughbreds, and Arabians. Prior to the start of any treatments (first week of January), body weight (BW) and body condition score (BCS; as described by Henneke et al. [11]), were recorded for each mare.

\subsection{Pretreatment Assessments, ECP-Sulpiride Treatment, and Blood Sampling}

On January 9, 2016, all mares were challenged intravenously with a combination of gonadotropin releasing hormone $(\mathrm{GnRH} ; 0.5 \mu \mathrm{g} / \mathrm{kg}$ of $\mathrm{BW})$ and sulpiride (racemic mixture; 4 $\mu \mathrm{g} / \mathrm{kg}$ of BW) obtained from Sigma-Aldrich, St. Louis, MO. Samples of jugular blood were drawn and 0, 10, 20 and 30 minutes relative to injection to characterize the $\mathrm{LH}$, follicle stimulating hormone (FSH), and prolactin responses. The blood samples were collected into 6$\mathrm{mL}$ evacuated tubes containing sodium heparin as an anticoagulant (Vacuette, Greiner Bio-One, Monroe, NC). The following day (January 10, 2016), all mares received an intramuscular injection in the neck of $50 \mathrm{mg}$ of ECP (BET Pharm, LLC, Lexington, KY). This was considered as day 0 of the experiment. 
A comparison of timing of the sulpiride injection component of the standard protocol was

112 overlayed on the experiment, such that approximately half the mares at each farm received

113 sulpiride on day 1 (10 mares, 6 at $\mathrm{BH}$ and 4 at $\mathrm{RBC}$ ) versus the rest that received sulpiride on

114 day 6 (13 mares, 8 at $\mathrm{BH}$ and 5 at $\mathrm{RBC}$ ). Sulpiride injections consisted of $3 \mathrm{~g}$ of the racemic

115 mixture of sulpiride suspended in $5 \mathrm{~mL}$ of vegetable shortening (Crisco; J.M. Smucker

116 Company, Orrville, $\mathrm{OH}$ ) administered subcutaneously in the girth area as previously described

117 by Thompson et al. [12]. Jugular blood samples were drawn at 0, 1, 3,6 and 24 hours relative to

118 injection of sulpiride, and then again every other day until February 28 (day 49). Plasma from

119 these samples was used for the determination of plasma prolactin, leptin, insulin, and insulin-like 120 growth factor-I (IGF-I) concentrations.

121

122

123

124

125

An additional jugular blood sample was collected from each mare on the day of ovulation and again for 5 successive days thereafter for determination of plasma LH and progesterone concentrations. For all blood samples collected throughout the experiment, plasma was harvested by centrifugation at $1200 \mathrm{x}$ g for 15 minutes and was stored at $-20^{\circ} \mathrm{C}$.

\subsection{Ultrasonography and Artificial Insemination}

Ovarian follicular activity was monitored via ultrasonography (Aloka 550V with 5-Mhz linear-array transducer; Hitachi-Aloka, Wallingford, CT) every 3 to 4 days until a follicle $25 \mathrm{~mm}$ or greater was detected, after which the mare was scanned daily until the follicle either reached $32 \mathrm{~mm}$ or greater, or regressed to $<25 \mathrm{~mm}$. Upon detection of a 32-mm follicle or greater, the mare was artificially inseminated with at least $500 \times 10^{6}$ progressively motile sperm from a stallion of proven fertility. After insemination, the mare was administered $0.75 \mathrm{mg}$ deslorelin (BET Pharm, Lexington, KY) intramuscularly to induce ovulation. Inseminated mares were scanned for pregnancy at 12 days after ovulation. If an embryonic vesicle was detected, the mare 
134 was scanned again at 16 and 22 days (+/- 1 day). Upon detection of a heartbeat at 22 days or

135 later, the pregnancy was terminated with a luteolytic dose of dinoprost (Lutalyse; Zoetis Inc.,

136 Kalamazoo, MI). Some mares ovulated before obtaining a 32-mm follicle, and were not

137 inseminated. Those mares, plus inseminated mares that did not conceive, were scanned every 3

138 to 4 days to determine their subsequent ovulation.

139

140

141

142

143

144

145

146

147

148

149

150

151

152

153

154

155

\subsection{Hormonal Assays}

Frozen plasma samples were thawed and analyzed for prolactin, FSH, LH, leptin, IGF-I, insulin, and progesterone as appropriate. Prolactin, FSH, LH, leptin and IGF-I were measured with radioimmunoassays previously validated by our laboratory [13-17]. Intra- and interassay coefficients of variation and levels of detection were $7 \%, 12 \%$ and $0.2 \mathrm{ng} / \mathrm{mL}$ for prolactin; $6 \%$, 9\%, and $0.2 \mathrm{ng} / \mathrm{mL}$ for $\mathrm{LH} ; 7 \%, 11 \%$, and $1.4 \mathrm{ng} / \mathrm{mL}$ for FSH; $5 \%, 12 \%$, and $8 \mathrm{ng} / \mathrm{mL}$ for IGF-I; and $4 \%, 8 \%$, and $0.8 \mathrm{ng} / \mathrm{mL}$ for leptin. Insulin and progesterone concentrations were measured with commercially available kit reagents (ImmuChem Coated Tube ${ }^{125}$ I RIA Kit and ImmuChem Double Antibody, ${ }^{125}$ I RIA Kit, respectively; MP Biomedicals, Costa Mesa, CA). The intra- and interassay coefficients of variation and assay sensitivities were $5 \%, 8 \%$, and $0.5 \mathrm{mIU} / \mathrm{L}$ for insulin and $5 \%, 9 \%$, and $0.05 \mathrm{ng} / \mathrm{mL}$ for progesterone. Estradiol was measured in acetoneextracted, $0.2 \mathrm{~mL}$ samples of plasma with commercially available kit reagents (MP Diagnostics Estradiol 17- $\beta$ Double Antibody, ${ }^{125}$ I RIA Kit); intra- and interassay coefficients of variation and assay sensitivities were $7 \%, 12 \%$ and $1.2 \mathrm{pg} / \mathrm{mL}$.

\subsection{Statistical Analyses}

Data for single-point dependent variables were analyzed by one-way analysis of variance (ANOVA) using the general linear model of SAS (SAS Instit., Cary, NC). Ovarian response was 
156 coded as 0 (no response) or 1 (response) for analysis (see below for treatment groups). Data for

157 dependent variables collected over multiple time points were analyzed by one-way ANOVA with

158 repeated sampling (split-plot design [18]) with the same software. Retrospective analysis showed

159 that all mares responding with early ovulation were located at one farm $(\mathrm{BH})$. Because of the

160 lack of success at RBC, analysis as a $2 \times 2$ factorial (with farm and success as the two factors)

161 was not possible, thus the treatments in the ANOVA were $\mathrm{BH}$ responding mares (BHR), $\mathrm{BH}$

162 non-responding mares (BHN), and RBC non-responding mares (RBCN) run individually.

163 Subsequently, although there were no mares responding at RBC to the original ECP-sulpiride

164 treatment, there were 3 mares that displayed more ovarian activity than the rest of the RBC

165 mares, and came close to, but did not achieve, the 32-mm follicle size for breeding. Thus, these

166 mares were lumped together into a fourth treatment group as RBC transitional (RBCT) for

167 analyses of endpoints that might affect success.

All dependent variables were subsequently re-analyzed with the 4 groups in the main

169 analyses (treatments), as well as the timing of sulpiride (1 versus 6 days after ECP) and its

170 interaction with treatment. Time (minutes for the challenges, days for other hormonal

171 characteristics) was included as the repeated factor as appropriate. One-degree of freedom

172 contrasts [18] were used to assess the effect of farm (BHN+BHR versus $\mathrm{RBCN}+\mathrm{RBCT})$ and the

173 difference between responding and non-responding mares at $\mathrm{BH}(\mathrm{BHN}$ versus $\mathrm{BHR})$ and

174 between the two groupings at $\mathrm{RBC}(\mathrm{RBCN}$ versus RBCT). The mares within group interaction,

175 which tested treatment in the repeated measures ANOVA, was used as the error term for these

176 comparisons.

\section{3. Results}

178 3.1. Ovarian Responses and Pregnancies 
An ovarian response was defined as the occurrence of a pre-ovulatory follicle at least 32

$\mathrm{mm}$ in diameter within 28 days after sulpiride injection, which either ovulated spontaneously or was induced to ovulate with deslorelin. Of the 23 mares treated with ECP and sulpiride, 9 responded with early ovulation (Table 1). The average days to ovulation for those mares responding was $11.7+/-1.0$, and ranged from 7 to 18 days post-sulpiride injection. There was no difference $(\mathrm{P}>0.1)$ in days to ovulation between mares receiving sulpiride on day 1 versus 6 after ECP. Mares not responding to the ECP-sulpiride treatment were scanned weekly until midMarch; no ovulation was detected in any of these mares up to that point.

Of the 9 mares that responded to treatment, all 9 were residents of the $\mathrm{BH}$ farm. At $\mathrm{RBC}$, there were 3 mares that grew follicles up to 28 to $30 \mathrm{~mm}$ without ovulation. Given that these were the only mares at RBC to show any ovarian response (albeit below threshold), they were readministered a second injection of sulpiride (same dose as previous) on day 42 (February 22) to determine if perhaps a potentiation had been induced that might lead to a quick response. They indeed responded with ovulatory sized follicles 12,13 , and 16 days after that second sulpiride treatment. Given that these mares stood out from the rest of the mares at RBC, they were placed in a separate group of their own (RBCT) for further analyses.

In the ANOVA for ovarian response, the RBCT mares were included as non-responding, given that they did not ovulate within the original 28-day period. Accordingly, there were only three treatment groups and no orthogonal contrast for RBCN versus RBCT. In that analysis, there was an effect $(\mathrm{P}=0.0059)$ of farm but no effect $(\mathrm{P}>0.1)$ of day of sulpiride injection nor any interaction with treatment.

Of the $9 \mathrm{BH}$ mares responding to treatment, 5 were artificially inseminated and induced to ovulate with deslorelin while the remaining 4 ovulated on their own without insemination or 
202 deslorelin treatment. Of the 5 that were bred, 3 conceived and carried a pregnancy to 22 days, at

203 which time the pregnancy was terminated. All pregnancies had morphologically normal

204 embryonic vesicles and formation of embryo proper with cardiac activity. The 3 additional mares

205 that received a second sulpiride treatment (RBCT group) were also treated with deslorelin and

206 inseminated, and all 3 became pregnant, again with normal embryonic vesicles and cardiac

207 activity. Thus, the overall pregnancy rate was 6 of 8 mares that were inseminated, or $75 \%$.

\subsection{Physical and Hormonal Characteristics of Responding and Non-responding Mares}

Mean body condition scores, ages, and BW are presented in Table 2. The BHR mares had a higher $\mathrm{BCS}(\mathrm{P}=0.06)$ than the non-responding mares at both farms, but did not differ from

211 RBCT mares. Age and weight were not different overall; however, contrast analyses (Table 3)

212 indicated that BHR mares had higher BCS $(\mathrm{P}=0.03)$ and weighed more $(\mathrm{P}=0.02)$ than $\mathrm{BHN}$ 213 mares.

Prior to ECP treatment, FSH and prolactin responses to the $\mathrm{GnRH}$ and sulpiride

215 challenges were not different (P > 0.1; Fig. 1) across the four groups of mares. Averaged over the

216 three post-GnRH sampling periods, mean concentrations of $\mathrm{LH}$ tended to be higher $(\mathrm{P}=0.106$;

217 Fig. 1) in BHR mares than in BHN mares.

Mean prolactin concentrations in every-other-day samples before and after treatment with

219 ECP plus sulpiride are presented in Fig. 2. Because there was no effect $(\mathrm{P}>0.1)$ of day of

220 sulpiride treatment on ovarian response, the data for all mares were normalized to day of

221 sulpiride treatment (rather than ECP injection). Overall, there was no effect $(\mathrm{P}>0.1)$ of farm, no

222 difference between responding and non-responding mares at $\mathrm{BH}$, and no difference between

223 mares in the RBCN and RBCT groups. 
Mean plasma LH concentrations before ECP treatment and over the next 18 days are

225 presented in Fig. 3. A significant effect of treatment $(\mathrm{P}=0.004)$ and an interaction $(\mathrm{P}<0.0001)$

226 between response and day were present between responding, non-responding, and RBCT mares,

227 with LH concentrations being greatest in BHR mares on days 10, 12, 14, 16, and 18 after ECP.

228 Luteinizing hormone concentrations were also greater $(\mathrm{P}<0.05)$ in $\mathrm{BHN}$ mares than in $\mathrm{RBCN}$ or

229 RBCT mares on days 14, 16 and 18 post ECP treatment.

Plasma estradiol concentrations after treatment with ECP were measured in $\mathrm{BH}$ mares only, given that no RBC mare ovulated within 28 days. There was no difference $(\mathrm{P}>0.1)$ in

232 plasma estradiol concentrations between the responding and non-responding mares at BH (Fig.

233 4). Plasma estradiol peaked 1 to 2 days post ECP treatment and started a slow decline through 234 day 16 after ECP.

Means for plasma IGF-I, leptin, and insulin concentrations are presented in Table 4.

236 Concentrations of IGF-I did not differ $(\mathrm{P}>0.1)$ among the four groups, nor was there any effect

237 of farm. There was an effect of treatment $(\mathrm{P}=0.01)$ on leptin concentrations as well as an

238 interaction between treatment and day $(\mathrm{P}<0.0001)$. Leptin concentrations were highest in RBCT

239 mares; however, the difference was due primarily to two of the mares in particular with higher

240 than normal leptin concentrations. Contrast analyses (Table 5) revealed that leptin concentrations

241 were higher $(\mathrm{P}=0.09)$ in the BHR mares than in the BHN mares, and were higher $(\mathrm{P}=0.003)$ in

242 the RBCT mares than in the RBCN mares. There was also an effect of treatment on insulin

243 concentrations $(\mathrm{P}=0.05)$, which were highest in RBCT and in BHR mares. Contrast analyses

244 (Table 5) showed that concentrations of insulin were higher $(\mathrm{P}=0.01)$ in $\mathrm{BHR}$ mares than in 245 BHN mares. 
All mares that responded with ovulation experienced a normal rise in progesterone and

247 decline in LH immediately following ovulation (Fig. 5). There was no difference $(\mathrm{P}>0.1)$

248 between mares that were induced to ovulate with deslorelin and inseminated and mares that

249 ovulated spontaneously and were not inseminated.

250

251

252

253

254

255

256

257

258

262

263

264

\section{Discussion}

The use of dopamine antagonist protocols to induce early ovulation in mares has met with varying results. Some mares respond similarly from season to season, while others either never respond or will respond one season, but not the next (E.L. Oberhaus, personal observation). The aim of this study was to retrospectively analyze factors that might contribute to or prevent a mare from responding to ECP and sulpiride with early follicular activity and ovulation. Also, while dopamine antagonist protocols to induce ovulation have repeatedly been studied in our lab and by others, it has not been determined whether ovulations induced by ECP-sulpiride are indeed fertile and whether the uterus would support early pregnancy.

In this study, all mares were treated with ECP and a single subcutaneous injection of sulpiride in vegetable shortening. Ten mares received sulpiride 1 day after ECP while 13 received sulpiride 6 days after ECP. Mitcham et al. [8] observed a tendency for prolactin response to be higher in mares receiving domperidone 1 day after ECP versus 6 days after ECP; however, in the present study, day of sulpiride treatment did not affect the degree to which prolactin concentrations were increased.

Ovarian success, as defined by ovulation within 28 days post sulpiride treatment, was relatively low in this experiment (9 of 23 mares, or 39\%), whereas all 9 responding mares were housed at one farm. Considering only mares at the BH farm, success was 9 of 14 mares, or $64 \%$. 
268 Success rates of 50 to $89 \%$ have been achieved in previous experiments [6-10], depending upon

269 the specific protocol used. The $89 \%$ success rate of Kelley et al. [6] was based on every-other-

270 day injections of estradiol benzoate followed by daily sulpiride injections started 11 days later.

271 Attempts to simplify that protocol into a single or double injection regimen is what has led to the

272 lower percentages of success. In the last experiment reported by Mitcham [10], a single injection

273 of ECP followed by three injections of sulpiride 5 days apart resulted in a success rate of $77 \%$.

274 Reducing the number of sulpiride injections to two, 5 days apart, produced a success rate of $63 \%$

275 (E.L. Oberhaus, personal observation). For the present experiment, the number of sulpiride

276 injections was reduced to one in an effort to simplify the protocol even further.

Pre-trial assessments of the $\mathrm{LH}, \mathrm{FSH}$, and prolactin responses to a standardized GnRH-

278 sulpiride challenge revealed no predictive information regarding FSH or prolactin responses

279 prior to ECP-sulpiride treatment. There was a tendency for a difference in LH response. The

280 tendency for a greater $\mathrm{LH}$ response to $\mathrm{GnRH}$ in BHR compared to BHN and RBCN may indicate

281 that the adenohypophyses of mares that would go on to respond to treatment were already more

282 competent in terms of LH synthesis and release, albeit low at that time of year. Given that no

283 mares had ovarian follicle(s) greater than $15 \mathrm{~mm}$ before the experiment started, all mares were

284 considered to be in a relatively "deep" anestrous-anovulatory state. This tendency of higher LH

285 response was evident in the responses to ECP injection, with the BHR mares having a much

286 greater rise in LH concentrations 10 to 18 days after ECP relative to BHN mares. The almost

287 total lack of $\mathrm{LH}$ response to ECP in the mares at RBC may account for the lack (or relative lack)

288 of ovarian stimulation.

289 Prolactin was stimulated in all mares for approximately 7 days by the injection of $3 \mathrm{~g}$ of

290 sulpiride in vegetable shortening. The response to sulpiride did not differ between mares that 
291 ovulated early and mares that did not, nor did it differ between the two farms. An important point

292 is that the responses were robust, with little variation, in contrast to what was often observed

293 with domperidone injections in previous experiments [7-9]. Thus, if there is indeed a threshold

294 level of prolactin concentrations that must be achieved for ovarian success, then it is likely that

295 all mares at both farms reached that threshold, whereas only mares at BH had sufficient LH

296 response to ECP to reach an ovulatory state. Previous injections of ECP alone, with no

297 dopaminergic antagonist to stimulate prolactin secretion, did not produce successful ovarian

298 responses [10]. In all our previous experiments with the estrogen-dopaminergic antagonist

299 combination, it has been consistent that both the prolactin response and the LH response to

300 estrogen must occur to some extent for the ovaries to respond. Failure of either results in zero

301 success.

It is well documented that nutrition and body condition play an important role in

303 reproduction $[19,20]$. Gentry et al. [20] demonstrated that low BCS of 3.0 to 3.5, produced by

304 nutrient restriction, resulted in low plasma leptin and IGF-I concentrations, low unstimulated

305 prolactin concentrations, a low LH response to GnRH, and an extended seasonal period of

306 anovulation with minimal follicular activity. Interestingly, the prolactin response to sulpiride

307 reported by Gentry et al. [20] did not differ between high and low BCS mares, much like that

308 observed in the present experiment. Albeit speculation, parallels can be seen between the

309 differences observed herein between responding and non-responding mares, and the results of

310 Gentry et al. [20]: low BW and BCS, low plasma leptin, low LH response to GnRH, and in this

311 experiment, low insulin concentrations.

In this experiment, plasma IGF-I concentrations did not differ between groups of mares,

313 but leptin and insulin were higher in the BHR than in the BHN mares even prior to treatment 
314 with ECP and sulpiride. These hormones are generally thought of as indicators of nutritional

315 status, with higher concentrations associated with better nutrition. For mares housed at the BH

316 farm, the differences would be consistent with that concept. For the RBC mares, the trends are in

317 the same direction, but did not meet statistical muster. Due to different winter management

318 schemes at the two farms, differences in nutritional availability were present, even though all

319 mares were housed on pasture without any grain supplementation. Retrospective investigation

320 revealed that the mares at the $\mathrm{BH}$ farm had access to round bales of Alicia bermuda grass hay,

321 winter ryegrass pasture, and ad libitum protein tubs (primarily cottonseed and soybean meals,

322 molasses, and added vitamin A). Mares at the RBC farm had access to round bales of coastal

323 bermuda and rye grass hay, but did not have access to winter ryegrass or protein

324 supplementation. These differences in potential nutrient intake may have contributed to the

325 failure of RBC mares to respond to the initial treatment.

The three RBC mares that were considered transitional due to significant follicular

327 activity (relative to the other nonresponding mares) with no ovulation had the highest leptin

328 concentrations of all mares in the four groups. Of those three mares, two had leptin

329 concentrations ranging from 2 to $5.5 \mathrm{ng} / \mathrm{mL}$ compared to $<2 \mathrm{ng} / \mathrm{mL}$ for most other mares at both

330 farms. It is possible that these mares were hyperleptinemic as a result of insulin insensitivity [16,

33121 , although no direct assessment of insulin sensitivity was performed. Hyperleptinemia is

332 typically associated with hyperinsulinemia, due to compensated insulin resistance [16, 21].

333 However, the mean insulin concentrations in these three mares were not outstanding relative to

334 the other mares at both farms. Insulin insensitivity per se is known to be associated with

335 perturbations in estrous cyclicity [23, 24], thus studies involving the use of sulpiride in these

336 mares deserve further research. The fact that these three mares responded so consistently and 
337 quickly to the second sulpiride injection on February 22 may indicate that the first ECP-sulpiride treatment established conditions within the ovaries that potentiated the response to subsequent 339 elevated prolactin concentrations. The effect of ECP and sulpiride on LH concentrations seems to be somewhat complex.

341 Clearly, estradiol has a stimulatory effect on LH secretion, and an increase in LH has not been 342 observed in mares receiving a dopamine antagonist alone [6-10]. Garcia and Ginther [25]

343 administered $1 \mathrm{mg}$ of estradiol daily to ovariectomized pony mares in February and observed an 344 increase in LH, but not until 6 days after initiation of treatment. Similarly, Kelley et al. [6] and 345 Mitcham [10] administered $11 \mathrm{mg}$ estradiol benzoate and $150 \mathrm{mg}$ ECP, respectively, to 346 seasonally anovulatory mares and did not observe an increase in LH until after treatment with 347 sulpiride 6 to 11 days after estrogen treatment. Moreover, Mitcham [10] administered sulpiride 348 or domperidone in biodegradable microparticles to mares simultaneously (same morning) as the 349 ECP injection and observed no increase in plasma LH concentrations over the next 21 days. The 350 question arises as to whether treatment with sulpiride after ECP enhances the LH response. In the 351 present study, an increase in LH was not observed until 10 days after ECP treatment. At that 352 point, concentrations of LH rose to levels similar to those seen around a typical, breeding season 353 ovulation, and appeared to coincide with late stage follicular growth and ovulation in those 354 (BHR) mares. Plasma estradiol in responding and non-responding mares at BH peaked one and 355 two days, respectively, after ECP treatment and then began to decline. Four of the 9 responding 356 mares exhibited a decline in circulating estradiol followed by a subsequent rise around the time 357 of each mare's respective ovulation; therefore, it is possible that LH is being stimulated by 358 endogenous follicular estradiol as well as the exogenous ECP. 
Mari et al. [5] assessed fertility following sulpiride treatment in anestrous mares. First

360 ovulation of the season was advanced in sulpiride-treated mares and pregnancy rates on the first

361 cycle were 40\% (4/10). In addition, Mari et al. [5] reported normal foalings in all pregnant

362 mares. Throughout the series of experiments with estrogen pretreatment coupled with

363 antidopaminergic agents that we have completed [6-10], this is the first time to test the actual

364 fertility of the ovulations induced by treatment. Although minimal in number, the percentage of

365 mares becoming pregnant after insemination is certainly within the expected range for mares

366 bred on one estrous cycle in spring and summer. More extensive studies are needed to confirm

367 whether the fertility of these induced ovulations are indeed equivalent to later breedings.

368 However, these data are encouraging for breeders who want to get their open mares pregnant

369 early in the year.

In conclusion, treatment with $50 \mathrm{mg}$ of ECP followed by $3 \mathrm{~g}$ of $+/$ - sulpiride in vegetable

371 shortening 1 or 6 days later elevated plasma prolactin concentrations in all mares for 6 to 8 days.

372 Given the robust responses across all mares, prolactin response could not be a factor in

373 determining whether a mare responded within 28 days or not (success). Assessments of plasma

374 FSH and prolactin responses to low-dose sulpiride and GnRH challenges provided no predictive

375 information as to future success. The tendency for higher LH response to GnRH in responding

376 mares prior to treatment may be indicative of the subsequent LH response and eventually the

377 ovarian response to ECP-sulpiride. Success was influenced by body condition and likely

378 nutritional status as indicated by higher plasma leptin and insulin concentrations in the

379 responding mares. We suspect that the likelihood of a seasonally anovulatory mare responding to

380 the treatment protocol used herein is inversely correlated to the "depth" of the anestrous state.

381 That depth of anestrus is known to be influenced by nutritional status as well as proximity to the 
382 seasonal transition period, as we [20] and others [26] have suggested in previous reports for

383 mares treated with only dopaminergic antagonists. Finally, from the limited inseminations

384 performed with these mares, we suspect that these induced ovulations are indeed fertile and can

385 produce at least 22-day embryos with heartbeats. Future research would be needed to better

386 clarify the actual fertility rate and to confirm that the pregnancies can be carried to term.

\section{Acknowledgements}

This work was supported by the USDA National Institute of Food and Agriculture, Hatch project 390 Accession Number 0224441.

The authors thank A. F. Parlow and the National Institute of Diabetes and Digestive and

392 Kidney Diseases, National Hormone and Pituitary Program, Harbor-University of California Los

393 Angeles Medical Center, Torrance, CA, for reagents.

394

$395 \quad$ References

396 [1] Nequin LG, King SS, Johnson AL, Gow GM, Ferreira-Dias GM. Prolactin may play a role in 397 stimulating the equine ovary during the spring reproductive transition. J Equine Vet Sci

$398 \quad 1993 ; 13: 631-5$.

399 [2] Thompson DL, Hoffman R, DePew CL. Prolactin administration to seasonally anestrous 400 mares: Reproductive, metabolic, and hair shedding responses. J Anim Sci 1997;75:1092-9.

401 [3] Besognet B, Hansen BS, Daels PF. Induction of reproductive function in anestrous mares 402 using a dopamine antagonist. Theriogenology 1997;47:467-80. 
403 [4] Brendemuehl JP, Cross DL. Influence of the dopamine antagonist domperidone on the vernal 404 transition in seasonally anoestrous mares. J Reprod Fertil 2000;(Suppl 56):185-93.

405 [5] Mari G, Morganti M, Merlo B, Castagnetti C, Parmeggiani F, Govoni N, Galeati G, Tamanini 406 C. Administration of sulpiride or domperidone for advancing the first ovulation in deep anestrous 407 mares. Theriogenology 2009;71:959-65.

408 [6] Kelley KK, Thompson DL, Storer WA, Mitcham PB, Gilley RM, Burns PJ. Estradiol 409 interactions with dopamine antagonists in mares: Prolactin secretion and reproductive traits. J. 410 Equine Vet Sci 2006;26:517-28.

411 [7] Mitcham PB, Thompson DL, Thompson TT, Bennett SD, Burns PJ, Caltabilota TJ.

412 Stimulation of ovulation in seasonally anovulatory and vernal transitional mares with estradiol 413 and domperidone: Dose and combination studies. J Equine Vet Sci 2010;30:244-8.

414 [8] Mitcham PB, Thompson DL, Burns PJ, Gilley RM, Hebert RC. Development of an estradiol415 dopamine antagonist protocol for inducing ovulation in seasonally anovulatory mares. J Equine 416 Vet Sci 2013;33:375-6.

417 [9] Mitcham PB, Thompson DL, Burns PJ, Gilley RM. Recent advances in the use of an 418 estradiol-dopamine antagonist protocol to induce ovulation in seasonally anovulatory mares. J 419 Equine Vet Sci 2014;34:105-6.

420 [10] Mitcham PB. Development of an estradiol-dopamine antagonist protocol for inducing 421 ovulation in seasonally anovulatory mares. PhD dissertation. Baton Rouge: Louisiana State 422 Univ; 2012. 
423 [11] Henneke DR, Potter GD, Kreider JL, Yeates BF. Relationship between condition score, 424 physical measurements and body fat percentage for mares. Equine Vet J 1983;15:371-6.

425 [12] Thompson DL, Oberhaus EL, Ferreira JC, Arana Valencia N. Prolactin secretion in 426 estrogen-primed geldings: Effect of dose and site of injection of sulpiride in a vegetable 427 shortening vehicle. J Equine Vet Sci 2015;35:443-4.

428 [13] Thompson DL Jr, Godke RA, Squires EL. Testosterone effects on mares during 429 synchronization with altrenogest: FSH, LH, estrous duration and pregnancy rate. J Anim Sci $430 \quad 1983 ; 56: 678-86$.

431 [14] Thompson DL Jr, Reville SI, Walker MP, Derrick DJ, Papkoff H. Testosterone 432 administration to mares during estrus: Duration of estrus and diestrus and concentrations of LH 433 and FSH in plasma. J Anim Sci 1983; 56:911-8.

434 [15] Colborn DR, Thompson DL Jr, Roth TL, Capehart JS, White KL. Responses of cortisol and 435 prolactin to sexual excitement and stress in stallions and geldings. J Anim Sci 1991;69:2556-62.

436 [16] Cartmill JA, Thompson DL, Storer WA, Gentry LR, Huff NK. Endocrine responses in 437 mares and geldings with high body condition scores grouped by high vs. low resting leptin 438 concentrations. J Anim Sci. 2003:81;2311-21.

439 [17] Sticker LS, Thompson DL, Fernandez JM, Bunting LD, DePew CL. Dietary protein and/or 440 energy restriction in mares: Plasma growth hormone, IGF-I, cortisol, and thyroid hormone 441 responses to feeding, glucose, and epinephrine. J Anim Sci. 1995b:73;1424-32. 
442 [18] Steel RGD, Torrie JH, Dickey DA. Principles and procedures of statistics: a biometrical 443 approach. 3rd ed. New York: McGraw-Hill; 1997.

444 [19] Henneke DR, Potter GD, Kreider JL. Body condition during pregnancy and lactation and 445 reproductive efficiency of mares. Theriogenology 1984;21:897-909.

446 [20] Gentry LR, Thompson DL, Gentry GT, Davis KA, Godke RA, Cartmill JA. The 447 relationship between body condition, leptin, and reproductive and hormonal characteristics of 448 mares during the seasonal anovulatory period. J Anim Sci. 2002;80:2695-703.

449 [21] Caltabilota TJ, Earl LR, Thompson DL, Clavier SE, Mitcham PB. Hyperleptinemia in 450 mares and geldings: assessment of insulin sensitivity from glucose responses to insulin injection. 451 J Anim Sci. 2010:88;2940-9.

452 [23] Sessions DR, Reedy SE, Vick MM, Murphy BA, Fitzgerald BP. Development of a model 453 for inducing transient insulin resistance in the mare: Preliminary implications regarding the 454 estrous cycle. J Anim Sci 2004:82;2321-8.

455 [24] Vick MM, Sessions DR, Murphy BA, Kennedy EL, Reedy SE, Fitzgerald BP. Obesity is 456 associated with altered metabolic and reproductive activity in the mare: Effects of metformin on 457 insulin sensitivity and reproductive cyclicity. Reprod Fertil Dev 2006:18;609-17.

458 [25] Garcia MC, Ginther OJ. Regulation of plasma LH by estradiol and progesterone in 459 ovariectomized mares. Biol Reprod 1978;19:447-53. 
460 [26] Daels PF, Fatone S, Hansen BS, Concannon PW. Dopamine antagonist-induced

461 reproductive function in anoestrous mares: gonadotropin secretion and effect of environmental

462 cues. J Reprod Fertil Suppl 2000:56;173-84. 
Table 1. Number of horses treated at each farm that responded with ovulation or a transition-like state.

\begin{tabular}{lcccc}
\hline Farm & $\begin{array}{c}\text { Day of Sulpiride } \\
\text { Treatment }\end{array}$ & n & $\begin{array}{c}\text { No. } \\
\text { Responding }\end{array}$ & $\begin{array}{c}\text { No. } \\
\text { Transition- } \\
\text { like }\end{array}$ \\
\hline RBC & 1 & 4 & $0(0 \%)$ & $1(25 \%)$ \\
& 6 & 5 & $0(0 \%)$ & $2(40 \%)$ \\
\hline BH & 1 & 6 & $5(83 \%)$ & $0(0 \%)$ \\
& 6 & 8 & $4(50 \%)$ & $0(0 \%)$ \\
\hline
\end{tabular}

Abbrev: RBC, Reproductive Biology Center; BH, Ben Hur Farm.

Table 2. Mean body condition score (BCS), age, and body weight for horses of the four response groups at the two farms.

\begin{tabular}{cccccc}
\hline & & Means & & $\begin{array}{c}\text { Treatment } \\
\text { effect }\end{array}$ \\
\hline & BHN & BHR & RBCN & RBCT & P-value \\
\hline BCS (1-9) & $5.2^{\mathrm{a}}$ & $6.5^{\mathrm{b}}$ & $5.2^{\mathrm{a}}$ & $5.3^{\mathrm{a}, \mathrm{b}}$ & 0.06 \\
Age (yrs) & 11 & 15 & 11 & 13 & 0.23 \\
Weight (kg) & 420.6 & 488.9 & 478.5 & 478.0 & 0.11
\end{tabular}

Abbrev: BHN, Ben Hur non-responders; BHR, Ben Hur responders; RBCN, RBC nonresponders; RBCT, RBC transition-like. 
Table 3. One-degree of freedom contrast analyses for body condition score (BCS), age, and body weight between farms and within farms.

\begin{tabular}{cccc}
\hline & $\begin{array}{c}\text { Between } \\
\text { Farms } \\
\text { P - value }\end{array}$ & $\begin{array}{c}\text { BHN vs. } \\
\text { BHR } \\
\text { P-value }\end{array}$ & $\begin{array}{c}\text { RBCN vs. } \\
\text { RBCT } \\
\text { P-value }\end{array}$ \\
\hline BCS & 0.25 & 0.03 & 0.84 \\
Age & 0.56 & 0.11 & 0.44 \\
Weight & 0.30 & 0.02 & 0.99 \\
\hline
\end{tabular}

Abbrev: BHN, Ben Hur non-responders; BHR, Ben Hur responders; RBCN, RBC non-responders; RBCT, RBC transition-like. 
Table 4. Mean plasma concentrations of IGF-I, leptin and insulin.

\begin{tabular}{|c|c|c|c|c|c|c|}
\hline \multicolumn{5}{|c|}{$\begin{array}{c}\text { Mean plasma concentration } \\
(\mathrm{ng} / \mathrm{mL})\end{array}$} & \multirow{2}{*}{\multicolumn{2}{|c|}{$\begin{array}{cc}\begin{array}{c}\text { Treatment } \\
\text { effect }\end{array} & \begin{array}{c}\text { Interaction } \\
\text { with day }\end{array} \\
\text { P-value } \\
\end{array}$}} \\
\hline & BHN & BHR & $\mathrm{RBCN}$ & RBCT & & \\
\hline IGF-I & 138.40 & 172.19 & 84.97 & 127.25 & 0.16 & 0.91 \\
\hline Leptin & $0.24^{\mathrm{a}}$ & $0.87^{\mathrm{b}}$ & $0.40^{\mathrm{a}, \mathrm{b}}$ & $1.85^{\mathrm{c}}$ & 0.01 & $<0.0001$ \\
\hline Insulin & $21.73^{\mathrm{a}}$ & $36.62^{\mathrm{b}}$ & $30.18^{\mathrm{a}, \mathrm{b}}$ & $37.08^{\mathrm{b}}$ & 0.05 & 0.33 \\
\hline
\end{tabular}

Table 5. One-degree of freedom contrast analyses for plasma IGF-I, leptin, and insulin concentrations between farms and within farms.

\begin{tabular}{cccc}
\hline & $\begin{array}{c}\text { Between } \\
\text { Farms } \\
\text { P-value }\end{array}$ & $\begin{array}{c}\text { BHN vs. } \\
\text { BHR } \\
\text { P-value }\end{array}$ & $\begin{array}{c}\text { RBCN vs. } \\
\text { RBCT } \\
\text { P-value }\end{array}$ \\
\hline IGF-I & 0.14 & 0.42 & 0.40 \\
Leptin & 0.06 & 0.09 & 0.003 \\
Insulin & 0.29 & 0.01 & 0.29
\end{tabular}

Abbrev: BHN, Ben Hur non-responders; BHR, Ben Hur responders; RBCN, RBC non-responders; RBCT, RBC transition-like. 
533 Fig. 1. Plasma luteinizing hormone (LH), follicle stimulating hormone (FSH), and prolactin

534 areas under the curve after intravenous injection of gonadotropin releasing hormone and

535 sulpiride 24 hours before ECP injections. The farm-response groups were: mares at the Ben Hur

536 farm that did not respond (BHN), those that did respond (BHR), and mares at the Reproductive

537 Biology Center farm that did not respond $(\mathrm{RBCN})$ and those that showed transitional-like

538 ovarian activity (RBCT). Number of mares per group were 5, 9, 6, and 3, respectively, for the

539 BHN, BHR, RBCN, and RBCT groups. ${ }^{\mathrm{a}, \mathrm{b}}$ Means for $\mathrm{LH}$ areas differ $(\mathrm{P}=0.11)$. Error variances

540 from the analyses of variance were $0.096,1218$, and 287 for $\mathrm{LH}, \mathrm{FSH}$, and prolactin,

541 respectively. The individual standard error of the means are shown by vertical lines with bars.

543 Fig. 2. Mean plasma concentrations of prolactin in response to subcutaneous sulpiride injections

544 in January (day 0). The farm-response groups were: mares at the Ben Hur farm that did not

545 respond (BHN), those that did respond (BHR), and mares at the Reproductive Biology Center

546 farm that did not respond $(\mathrm{RBCN})$ and those that showed transitional-like ovarian activity

547 (RBCT). Number of mares per group were 5, 9, 6, and 3, respectively, for the BHN, BHR,

548 RBCN, and RBCT groups. No differences $(\mathrm{P}>0.05)$ were detected between any of the four

549 groups of mares. Pooled standard errors of the means from the analysis of variance were 7.38,

$550 \quad 5.5,6.73$, and $9.52 \mathrm{ng} / \mathrm{mL}$, respectively.

552 Fig. 3. Mean plasma concentrations of LH before ECP treatment (day 0) and over the next 18 553 days in Ben Hur responding mares (BHR), Ben Hur non-responding mares (BHN), RBC non554 responding mares $(\mathrm{RBCN})$, and $\mathrm{RBC}$ transitional mares (RBCT). A significant effect of group (P 
$555=0.004)$ and an interaction $(\mathrm{P}<0.0001)$ between group and day were present between

556 responding, non-responding, and transitional mares, with LH concentrations being greater in

557 BHR mares on days 10, 12, 14, 16, and 18 post ECP. Luteinizing hormone concentrations were

558 also greater $(\mathrm{P}<0.05)$ in BHN mares than in RBCN or RBCT mares on days 14,16 and 18 post

559 ECP treatment. Pooled standard errors of the means from the analysis of variance were 0.54 ,

$5600.41,0.5$, and $0.7 \mathrm{ng} / \mathrm{mL}$, respectively. Asterisks $\left(^{*}\right)$ indicate differences between BHR and all

561 other groups; double daggers (\$) indicate differences between BHN and all other groups.

563 Fig. 4. Mean plasma estradiol concentrations in mares at the Ben Hur farm after treatment with

$56450 \mathrm{mg}$ of ECP on day 0. Estradiol concentrations in mares at the Reproductive Biology Center

565 farm were not assessed given that no mare responded on that farm with a 32-mm or greater

566 follicle within 28 days. Pooled standard error of the mean from the analysis of variance was 2.13

$567 \mathrm{pg} / \mathrm{mL}$.

568

569 Fig. 5. Mean plasma LH and progesterone concentrations on day of ovulation (day 0) and for 5

570 successive days after. No differences existed $(\mathrm{P}>0.1)$ between mares that were induced to

571 ovulate with deslorelin and inseminated and mares that ovulated spontaneously and were not

572 inseminated. Pooled standard errors of the means from the analysis of variance were $1.7 \mathrm{ng} / \mathrm{mL}$

573 for $\mathrm{LH}$ and $0.99 \mathrm{ng} / \mathrm{mL}$ for progesterone. 

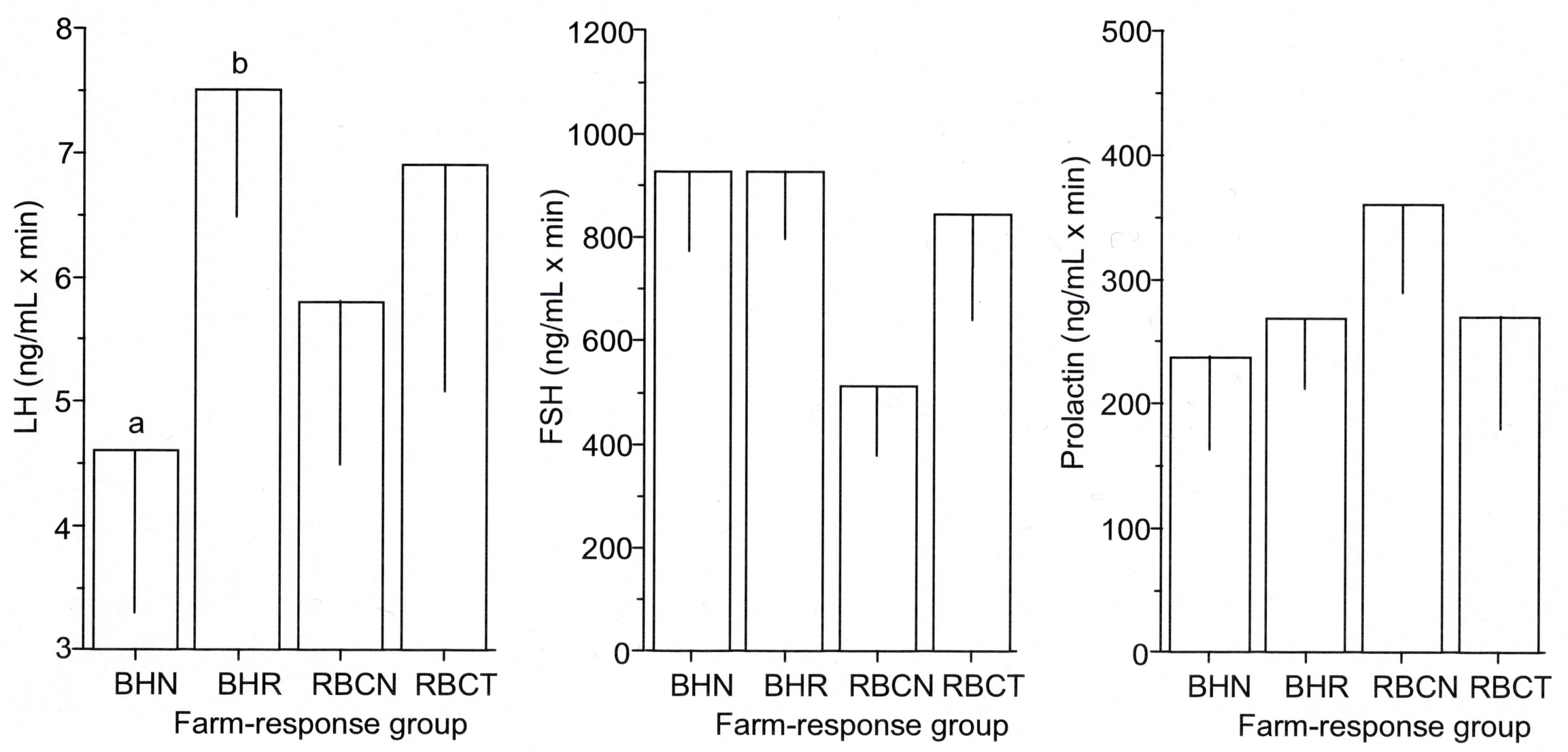


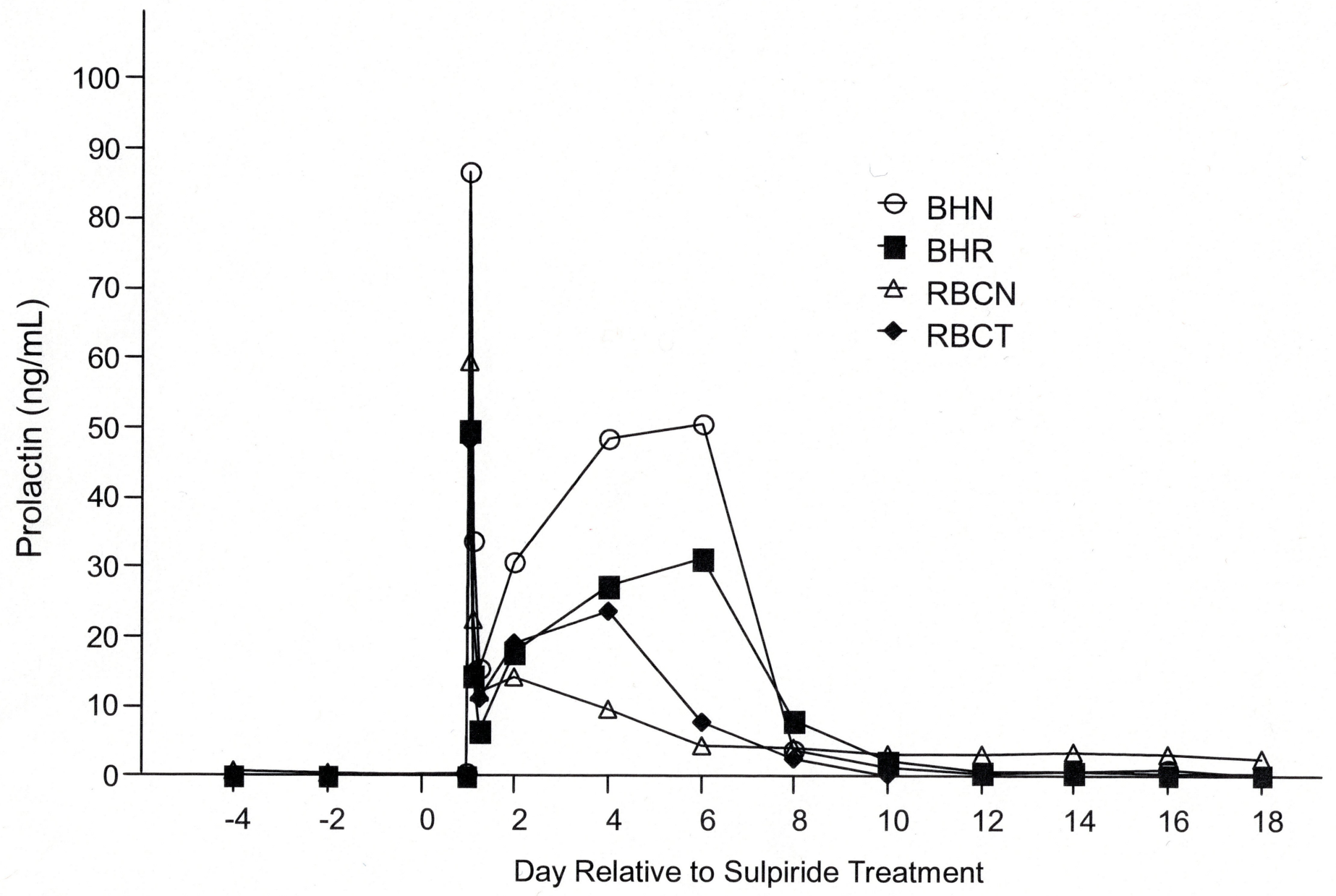




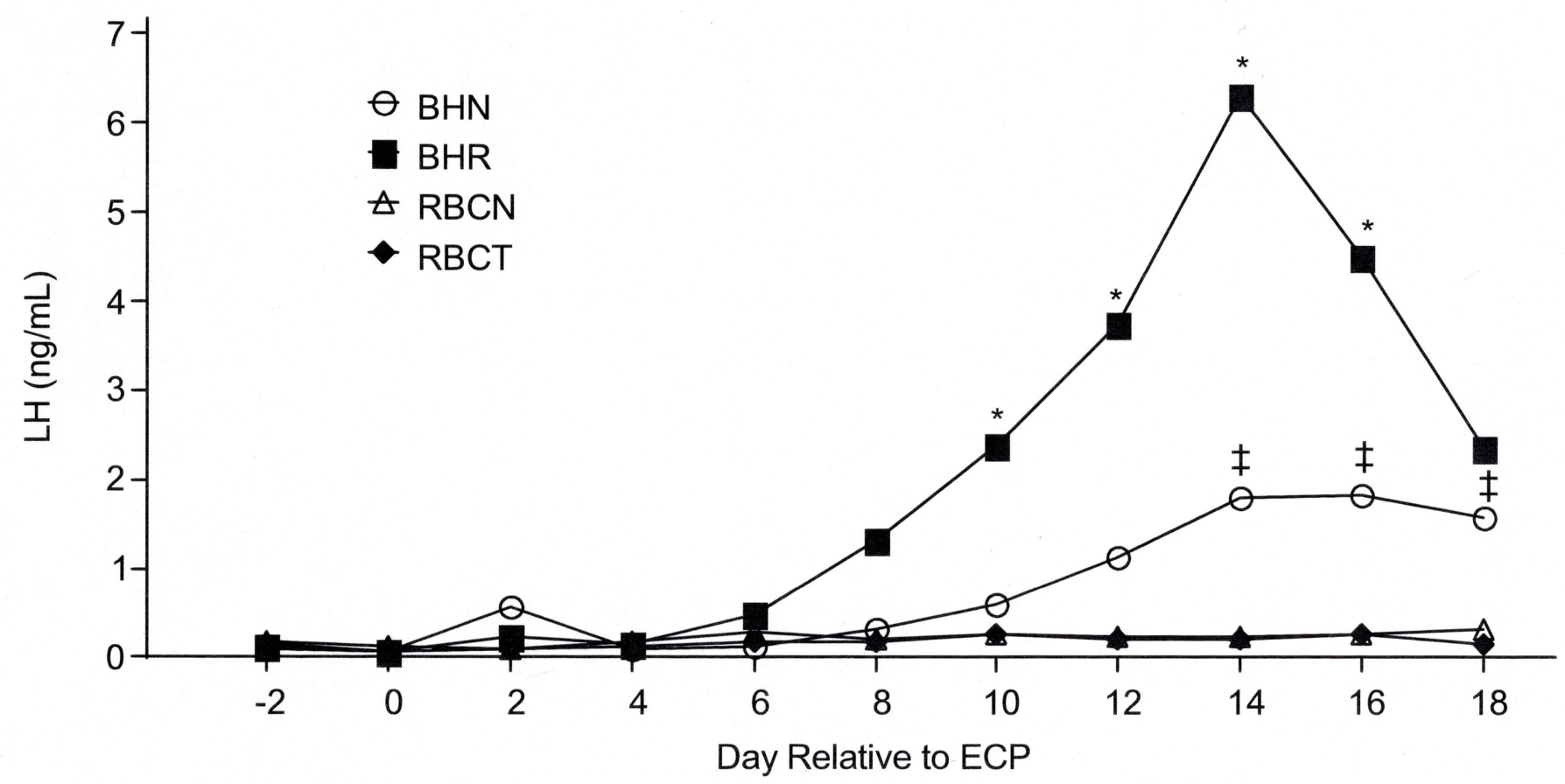




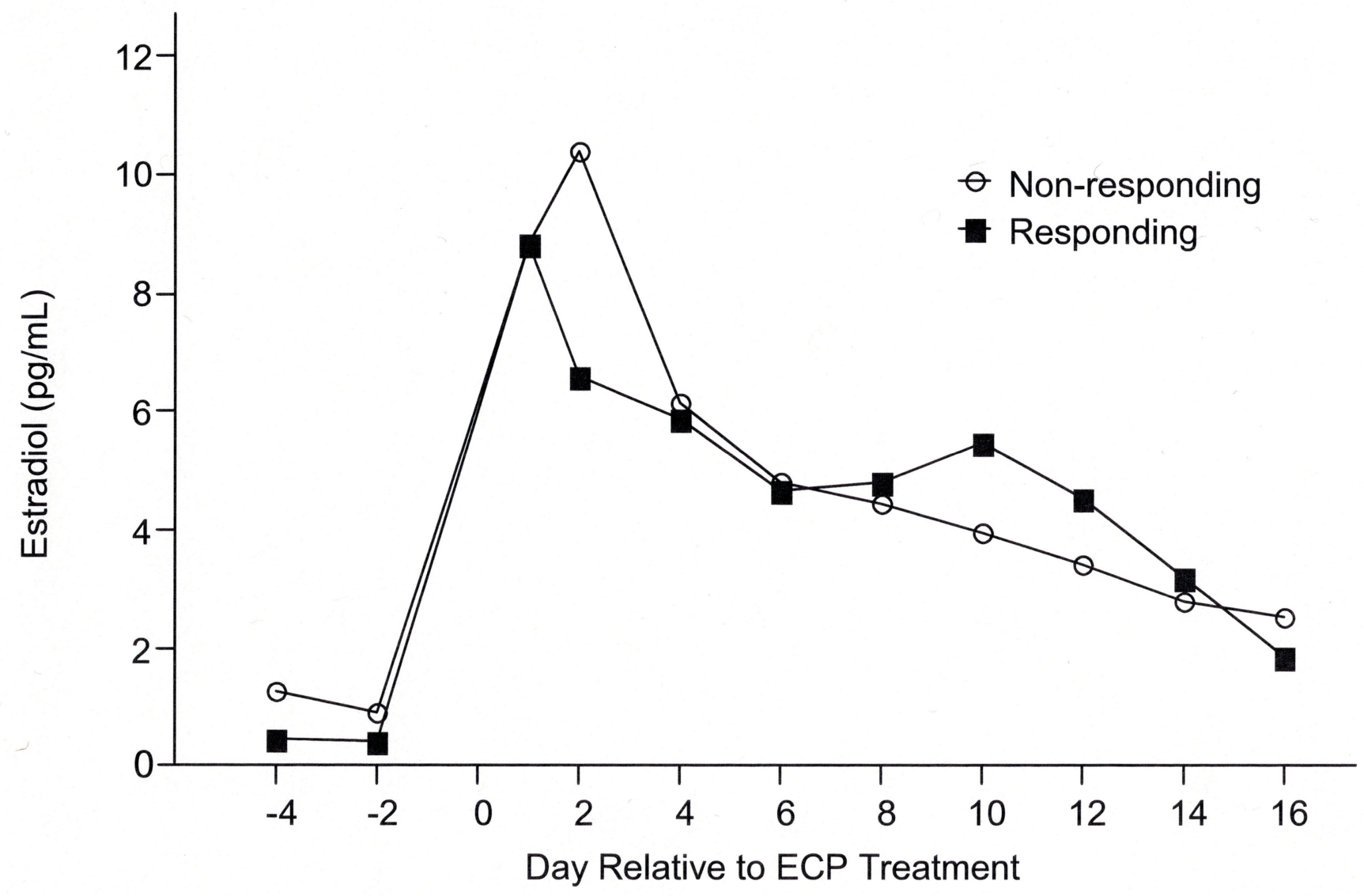




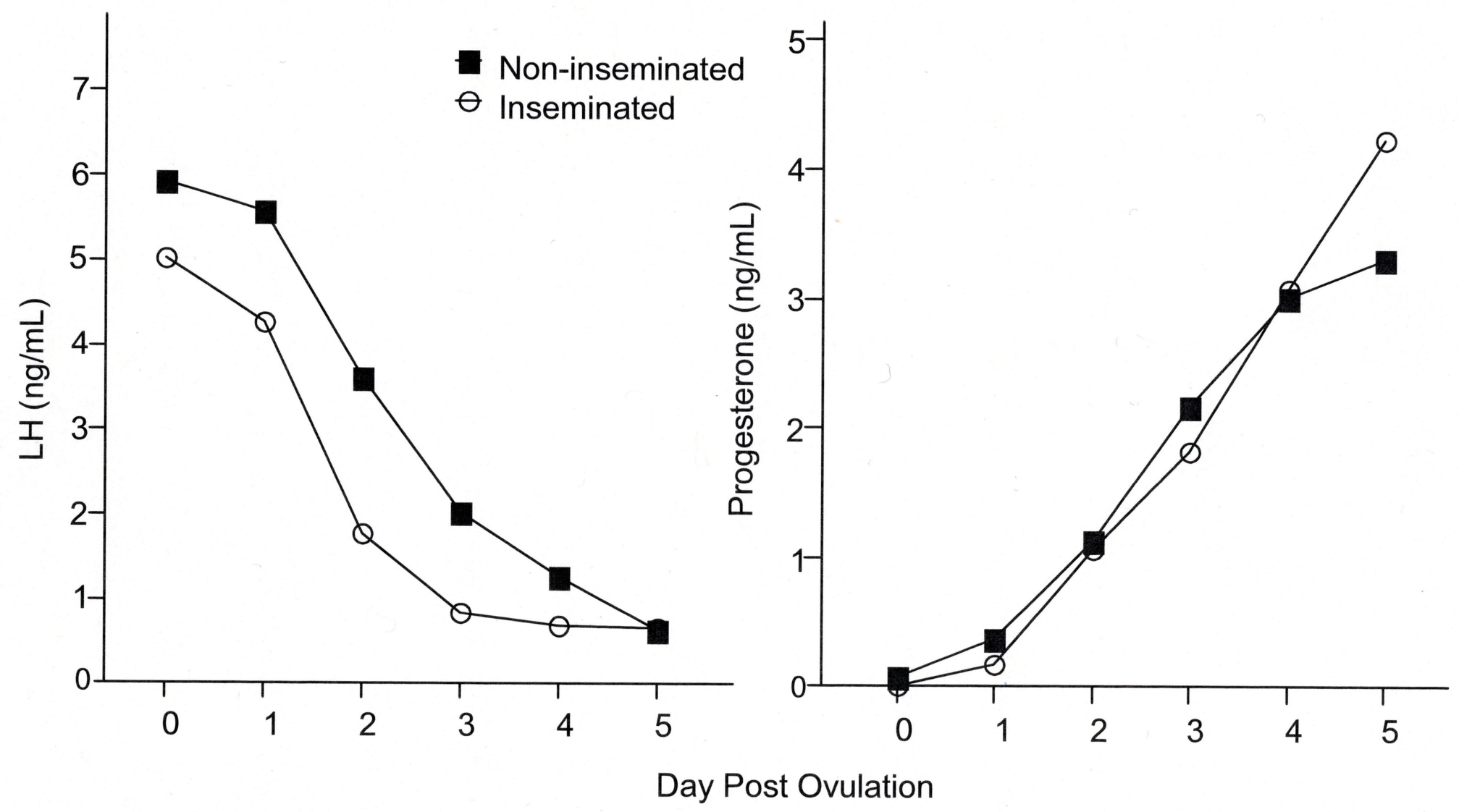

